\title{
Un itinerario "encantado" por la ciudad de Granada. Propuestas innovadoras de inclusión en la E.S.O.
} An "enchanted" itinerary throught the city of Granada. Innovative proposals for
inclusión in the E.S.O.

Javier Contreras García

Universidad Granada. Departamento de Didáctica de las Ciencias Sociales, (España)

jcontreras@ugr.es

Fecha recepción: 03/09/2019

Páginas 106-119

Fecha aceptación: 25/11/2019

\section{Resumen.}

La siguiente propuesta de Itinerario Didáctico, tiene como fin realizar una puesta en valor del Patrimonio de la Ciudad de Granada como elemento didáctico para alumnado de la E.S.O, basándose en una metodología original e innovadora para tratar de fomentar la curiosidad e interés del alumnado en materias relacionadas con las Ciencias Sociales como son: la Geografía, la Historia y la historia del Arte; al tiempo que propone una actividad trasversal innovadora e inclusiva, que, creemos puede ser altamente beneficiosa para el colectivo de alumnos de esta etapa educativa. Nuestro itinerario supondría una herramienta motivacional, al basarse en edificios "encantados" de la ciudad de Granada, lo cual supone un elemento de interés para el alumnado que, además, supondrá una actividad extracurricular, con la que, como hemos comprobado, se fomentan aspectos como el trabajo en equipo, la sociabilización del alumnado, la integración, la multiculturalidad o la transversalidad entre distintas materias.

Palabras clave: itinerario; patrimonio; inclusión; ciencias sociales; transversalidad

\section{Abstract.}

The following proposal for a Didactic Itinerary, aims to make a value enhancement of the Heritage of the City of Granada as a didactic element for students of E.S.O, based on an original and innovative methodology to try to encourage curiosity and interest of students in subjects related to Social Sciences such as: Geography, History and Art History; At the same time, it proposes an innovative and inclusive cross-cutting activity, which, we believe, can be highly beneficial for the group of students of this educational stage. Our itinerary would be a motivational tool, based on buildings "enchanted" of the city of Granada, which is an element of interest for students that, in addition, will be an extracurricular activity, with which, as we have seen, aspects are promoted such as teamwork, student socialization, integration, multiculturalism or transversality between different subjects. 
Keywords: itinerary; heritage; inclusion; social sciences; tranversality

\section{1.-Introducción.}

La idea de este trabajo, es la de incentivar la curiosidad del alumnado de la E.S.O, fundamentalmente, aunque puede ser aplicado a cualquier nivel educativo, en lo referente a materias de Humanidades y Ciencias Sociales, como serían la Historia 0 la Historia del Arte.

Siguiendo un estudio realizado por el Grupo de Investigación Meridiano HUM 200, de la Universidad de Granada: "El elevado fracaso escolar en las asignaturas de Geografía y de Historia en segundo de Bachillerato, en los exámenes de selectividad del distrito universitario de Granada, que alcanza una media del 32,26\% de suspensos en las dieciséis convocatorias realizadas entre 1989 y 2006, constituyen otra razón de peso que justifica suficientemente esta investigación, (Se refiere a la Teoría de los Principios Científico-Didácticos) y no sólo por los datos que en sí misma nos ofrece, sino porque supone una muestra representativa de una situación más generalizada y extendida a otros lugares y niveles". (García Ruiz y Jiménez López, 2006).

Las preferencias de los alumnos a la hora de elegir carrera, parecen basarse más en las preferencias personales, que en las salidas profesionales de las mismas, aún así la elección de Grados como los de Geografía, Historia o Historia del Arte, a pesar de seguir acumulando alumnos, suelen tener la percepción de contar con pocas salidas laborales. Nos haremos eco de una noticia que, a su vez, sigue un informe del Ministerio de Educación que dice: Uno de cada dos titulados universitarios en nuestro país -según el informe del Ministerio de Educación sobre egresados universitarios y afiliación a la Seguridad Social- son de la rama de Ciencias Sociales y Jurídicas, cuando el actual mercado laboral demanda claramente titulados con un perfil mucho más técnico. En el informe Infoempleo de Adecco de 2013 esta tendencia es evidente. El 42,08\% de las ofertas de empleo pertenecen al sector de Técnica e ingenierías, frente al $37,95 \%$ de la rama de Ciencias Sociales y Jurídicas, el 15,27\% de Ciencias o el 4,7\% de Humanidades. Mientras que carreras como Matemáticas, Informática o Química exigen notas de corte (acceso a la Universidad) muy bajas porque no hay demanda para estudiarlas, pese a ser las que tienen tasas de empleabilidad más altas, otras con mala salida laboral, como Publicidad y Relaciones Públicas o Comunicación Audiovisual, Bellas Artes y Periodismo, exigen unas notas altísimas por la elevada demanda para estudiar en ellas. A la luz de estos números, podría parecer que las elecciones de carreras como Geografía, Historia o Historia del Arte es numerosa con respecto a otras, pero la verdad es que a pesar de que aún cuenta con numeroso alumnado, al menos en la Universidad de Granada, esta elección final de la temática de Carrera, no coincide, al menos con las preferencias en edades tempranas, como suele ocurrir al cuestionar a alumnos de la E.S.O sobre sus materias favoritas. Por tanto, en ocasiones no conseguimos llegar al alumnado, fallando en la forma de transmisión de estas materias para hacerlas más atractivas. La idea por tanto de este Itinerario Didáctico es realizar una puesta en valor de una serie de edificios del centro de la ciudad de Granada, de forma que pongamos en práctica la enseñanza de materias como la Historia y la Historia del Arte de una 
forma diferente y quizá más atractiva. Para ello, realizamos un cuestionario previo, que, como veremos más adelante, demostrará que nuestra propuesta, supone un aliciente para los alumnos de los ciclos de la E.S.O que hace más interesante una actividad como esta, y una manera más divertida de acercar nuestro Patrimonio.

\section{2.-Los Itinerarios Didácticos como elementos de Inclusión.}

Siguiendo a: Arias, Contreras, Czestochowa y Tenedor: "Asimismo, a la hora de abordar el tema de la inclusión suele ser también más común y más fácil de percibir la necesidad de adaptar las medidas pedagógicas cuando el alumnado presenta una discapacidad física a cuando el alumnado presenta necesidades de tipo social. En este último caso no sólo es imprescindible un apoyo gubernamental (leyes, recursos económicos, dotación de personal especializado...), sino que el pesquis del docente en cuestión será el encargado de buscar los recursos que tenga a la mano para "enganchar" al alumnado con necesidades y al resto sus compañeros en su andadura con ellos" (Arias, Contreras, Czestochowa, Tenedor, 2019). Quizá en ocasiones, y en niveles como la E.S.O, fallamos más como docentes en la forma de transmitir el conocimiento, que en el hecho en sí de que nuestros alumnos encuentren interesantes las materias como tales. Los problemas de integración en el aula para alumnado con necesidades (no tienen que ser alumnos con diversidad, si no simplemente con problemas de sociabilización), encuentran una buena herramienta para corregir estas dificultades, en actividades extracurriculares como bien puede ser este itinerario.

Para otros autores, los Itinerarios incluso tienen una vertiente social en el aspecto comunitario, fomentando el sentimiento de pertenencia a un lugar y cultura. "Partiendo de este valor inclusivo que tiene el Patrimonio cultural, los modelos, propuestas o estrategias educativas desarrolladas en torno a él tienen además la posibilidad de fortalecer y visibilizar de la diversidad cultural que encierran las aulas de los centros educativos frente a los intentos de homogeneidad cultural dominantes en la escuela actual en diversos contextos geográficos. Así, el alumnado sentirá potenciada su identidad individual, reconociendo el valor de la diversidad, dentro de una identidad colectiva empleando el Patrimonio cultural como herramienta inclusiva para crear los puentes necesarios entre lo propio y lo ajeno, lo común y lo diferente" (Martínez, López, Santacanamestre, 2015: 96).

\section{1.- El valor de los Itinerario Culturales-Didácticos.}

Este elemento como tal, como herramienta didáctica, ha quedado acreditado con el uso y puesta en valor de los mismos en los últimos años. El ICOMOS (International Council on Monuments and Sites) elaboró la Carta de Itinerarios Culturales, donde define y pone en valor los planteamientos llevados a cabo durante la realización de los Itinerarios. Así, entiende: "el desarrollo de las ciencias de la conservación del patrimonio, el concepto de Itinerario Cultural evidencia la evolución de las ideas respecto a la visión de éste, así como la importancia creciente de los valores del entorno y de la escala territorial, y pone de manifiesto la macro estructura del 
patrimonio a diferentes niveles". [...] "Los Itinerarios Culturales representan procesos interactivos, dinámicos, y evolutivos de las relaciones humanas interculturales que reflejan la rica diversidad de las aportaciones de los distintos pueblos al patrimonio cultural".

Por tanto, valores que podemos encontrar en la realización de un Itinerario serán: la Inclusión, la sociabilización del alumnado, la Educación en Valores, el sentido de pertenencia a una comunidad, así como valores meramente de aprendizaje como serán: la puesta en valor de materias como la Historia y la Historia del Arte (en una vertiente más local), y como veremos más adelante, campos transversales como serán la Geografía Humana o la música.

\section{3.-Objetivos de este Itinerario.}

Valorar cada uno de los edificios que incluye este Itinerario, su historia tanto la histórico-artística, (estilo, elementos arquitectónicos, etc) como la vivida en cada monumento, de lo que serán muestra las leyendas fantasmales de cada uno.

Conocer el origen y finalidad de cada uno de los edificios.

Diferenciar la pluralidad de estilos artísticos, tanto de los edificios que contengan más de un estilo, como el de cada edificio en sí.

Conocer a los principales autores de cada edificio.

Percibir factores históricos, leyendas sobre las situaciones vividas en cada edificio y su historia, tango oficial como particular, conocer la historia de la ciudad y sus transformaciones urbanísticas con la Conquista de los Reyes Católicos, así como las sensaciones que trasmite el conocimiento de sus leyenda a nuestros alumnos.

Promover valores como la difusión y puesta en valor de la Historia local y del Patrimonio Histórico-Artístico de Granada.

\section{4.-Legislación, Contenidos y Competencias Clave.}

La idea de este Itinerario es realizar una actividad extracurricular por le Centro Histórico de la ciudad de Granada, visitando edificios cuyo nexo de unión sea la supuesta existencia de "fantasmas" o "historias paranormales" entendiendo estos dos referentes como un elemento motivacional para nuestro alumnado. Antes de nada nos centraremos en la legislación para seleccionar Contenidos y Competencias en los que enmarcar nuestro Itinerario. Como Marco Legislativo Fundamental, seguimos las 4 leyes, tanto Nacionales como Autonómicas, que rigen actualmente la Enseñanza Secundaria en España:

Tabla 1.

Real Decreto 1105-2014, Orden ECD-65-2015, D.A. 111-2016 y la Orden 14 de julio de 2016 de Andalucía.

$2^{\circ}$ de E.S.O CIENCIAS SOCIALES - GEOGRAFÍA E HISTORIA

\begin{tabular}{cllll}
\hline CONTENIDOS & CRITERIOS & DE & ESTÁNDARES & DE \\
& EVALUACIÓN & APRENDIZAJE & \\
\hline El arte románico y gótico & Comprender las funciones & 7.1. & Describe \\
\hline
\end{tabular}




\begin{tabular}{lllr}
\hline e islámico. La cultura en & diversas del arte en la & $\begin{array}{l}\text { características del arte } \\
\text { la Edad Media. El }\end{array}$ \\
$\begin{array}{l}\text { rodad Media. } \\
\text { patrimonio artístico } \\
\text { medieval. gótico }\end{array}$ & & \\
\hline
\end{tabular}

Bloque 2. HISTORIA. LA EDAD MODERNA

\begin{tabular}{|c|c|c|}
\hline CONTENIDOS & $\begin{array}{l}\text { CRITERIOS DE } \\
\text { EVALUACIÓN }\end{array}$ & $\begin{array}{l}\text { ESTÁNDARES DE } \\
\text { APRENDIZAJE }\end{array}$ \\
\hline $\begin{array}{l}\text { La Edad Moderna: el } \\
\text { Renacimiento y el } \\
\text { Humanismo; su alcance } \\
\text { posterior. El arte } \\
\text { Renacentista. }\end{array}$ & $\begin{array}{l}\text { 1.Comprender la } \\
\text { significación histórica de } \\
\text { la etapa del Renacimiento } \\
\text { en Europa. }\end{array}$ & $\begin{array}{l}\text { 1.1. Distingue diferentes } \\
\text { modos de periodización } \\
\text { histórica (Edad Moderna, } \\
\text { Renacimiento, Barroco, } \\
\text { Absolutismo). }\end{array}$ \\
\hline $\begin{array}{l}\text { Relevancia de la Corona } \\
\text { de Castilla en la obra } \\
\text { americana. Arte y cultura } \\
\text { en la América Hispana. } \\
\text { Las monarquías }\end{array}$ & $\begin{array}{l}\text { 2. Relacionar el alcance } \\
\text { de la nueva mirada de los } \\
\text { humanistas, los artistas y } \\
\text { científicos del } \\
\text { Renacimiento con etapas } \\
\text { anteriores y posteriores. }\end{array}$ & $\begin{array}{l}\text { 1.2. Identifica rasgos del } \\
\text { Renacimiento y del } \\
\text { Humanismo en la historia } \\
\text { europea, a partir de } \\
\text { diferentes tipos de fuentes } \\
\text { históricas. }\end{array}$ \\
\hline $\begin{array}{l}\text { modernas. La unión } \\
\text { dinástica de Castilla y } \\
\text { Aragón. Isabel I de } \\
\text { Castilla. }\end{array}$ & $\begin{array}{l}\text { 3.Analizar el reinado de } \\
\text { los Reyes Católicos como } \\
\text { una etapa de transición } \\
\text { entre la Edad Media y la } \\
\text { Edad Moderna. }\end{array}$ & $\begin{array}{l}\text { 2.1. Conoce obras y } \\
\text { legado de artistas, } \\
\text { humanistas y científicos } \\
\text { de la época. }\end{array}$ \\
\hline $\begin{array}{l}\text { El siglo XVII en Europa. } \\
\text { Las monarquías } \\
\text { autoritarias, absolutistas y } \\
\text { parlamentarias. } \\
\text { El arte Barroco. }\end{array}$ & $\begin{array}{l}\text { 4.Entender los procesos } \\
\text { de conquista y } \\
\text { colonización, y sus } \\
\text { consecuencias. }\end{array}$ & $\begin{array}{l}\text { 3.1. Conoce los } \\
\text { principales hechos de la } \\
\text { expansión de Aragón y de } \\
\text { Castilla por el mundo. }\end{array}$ \\
\hline \multirow[t]{2}{*}{$\begin{array}{l}\text { Principales } \\
\text { manifestaciones de la } \\
\text { cultura de los siglos XVI y } \\
\text { XVII. EI Siglo de Oro: arte } \\
\text { y cultura. }\end{array}$} & $\begin{array}{l}\text { 5.Comprender la } \\
\text { diferencia entre los reinos } \\
\text { medievales y las } \\
\text { monarquías modernas. } \\
\text { 6.Conocer rasgos de las } \\
\text { políticas internas y las } \\
\text { relaciones exteriores de } \\
\text { los siglos XVI y XVII en } \\
\text { Europa. }\end{array}$ & $\begin{array}{l}\text { 5.1. Distingue las } \\
\text { características de } \\
\text { regímenes monárquicos } \\
\text { autoritarios, absolutistas y } \\
\text { parlamentarios. } \\
\text { 7.1. Analiza obras (o } \\
\text { fragmentos de ellas) de } \\
\text { algunos autores de esta } \\
\text { época en su contexto. }\end{array}$ \\
\hline & $\begin{array}{l}\text { 7. Conocer la importancia } \\
\text { de algunos autores y } \\
\text { obras en los siglos XVI y } \\
\text { XVII. }\end{array}$ & $\begin{array}{l}\text { 8.1. Identifica obras } \\
\text { significativas del arte } \\
\text { Barroco. }\end{array}$ \\
\hline
\end{tabular}




\section{Conocer la importancia del arte Barroco en Europa y en América. Utilizar el vocabulario histórico con precisión, insertándolo en el contexto adecuado.}

Tabla de elaboración propia siguiendo materia procedente de los siguientes libros de texto de las editoriales: Grazalema, Santillana y Oxford Educación.

\section{1-Objetivos a seguir según la legislación vigente y Competencias Clave.}

Seleccionamos de entre los objetivos de la legislación andaluza los que se relacionan con nuestro Itinerario, véase:

b) Desarrollar y consolidar hábitos de disciplina, estudio y trabajo individual y en equipo como condición necesaria para una realización eficaz de las tareas del aprendizaje y como medio de desarrollo personal.

c) Valorar y respetar la diferencia de sexos y la igualdad de derechos y oportunidades entre ellos. Rechazar la discriminación de las personas por razón de sexo 0 por cualquier otra condición 0 circunstancia personal 0 social. Rechazar los estereotipos que supongan discriminación entre hombres y mujeres, así como cualquier manifestación de violencia contra la mujer.

d) Fortalecer sus capacidades afectivas en todos los ámbitos de la personalidad y en sus relaciones con los demás, así como rechazar la violencia, los prejuicios de cualquier tipo, los comportamientos sexistas y resolver pacíficamente los conflictos.

e) Desarrollar destrezas básicas en la utilización de las fuentes de información para, con sentido crítico, adquirir nuevos conocimientos. Adquirir una preparación básica en el campo de las tecnologías, especialmente las de la información y la comunicación.

f) Concebir el conocimiento científico como un saber integrado, que se estructura en distintas disciplinas, así como conocer y aplicar los métodos para identificar los problemas en los diversos campos del conocimiento y de la experiencia.

g) Desarrollar el espíitu emprendedor y la confianza en sí mismo, la participación, el sentido crítico, la iniciativa personal y la capacidad para aprender a aprender, planificar, tomar decisiones y asumir responsabilidades.

h) Comprender y expresar con corrección, oralmente y por escrito, en la lengua castellana, textos y mensajes complejos, e iniciarse en el conocimiento, la lectura y el estudio de la literatura.

l) Apreciar la creación artística y comprender el lenguaje de las distintas manifestaciones artísticas, utilizando diversos medios de expresión y representación. 
j) Conocer, valorar y respetar los aspectos básicos de la cultura y la historia propias y de los demás, así como el patrimonio artístico y cultural.

\section{5.-El Itinerario.}

Pretendemos con esta actividad que nuestro itinerario sea más o menos asequible, y sin apenas dificultad para que se adapte a las necesidades de cualquier persona. Por tanto lo llevaremos a cabo en el centro de Granada, en una zona relativamente llana, sin dificultad especial para su realización, de forma organizada y entre espacios relativamente cercanos. Los espacios que articularán nuestro Itinerario, como edificios simbólicos que vamos a estudiar serán los siguientes: La Casa de Castril, La Real Chancillería, el Conservatorio Superior de Música Victoria Eugenia (Palacio de los Marqueses de Caicedo) y el Hospital Real.

\section{1.-Cuestionario Previo.}

Para la realización de esta actividad, surgió la idea de crear un cuestionario previo. Este se llevó a cabo en el Centro de Enseñanza Secundaria Concertado Ave María de la localidad granadina de Albolote. El cuestionario constaba de 16 ítems, y estaba diseñado para evaluar lo que los alumnos sabían sobre temas como: su conocimiento previo sobre Itinerarios, así como de cada uno de los edificios incluidos en el mismo, sus gustos personales sobre materias como la Historia o la Historia del Arte, o el grado de interés que le suscitaban los edificios incluidos en el Itinerario; para finalmente aclarar, que el nexo de unión entre los monumentos seleccionados era que todos ellos tenían "fantasmas" o contaban con historias paranormales.

La realización del cuestionario fue guiada por nosotros en todo momento, de forma que los alumnos no tuvieron acceso a todas las preguntas de una sola vez, con lo cual no supieron que los edificios estaban "encantados" hasta el final, lo que nos aseguraba que sus respuestas no podían estar sugestionadas en este sentido, algo que será importante más adelante. Además los alumnos tenían total libertad a la hora de realizar los cuestionarios, ya que a cada pregunta-ítem le correspondía un espacio en blanco que cada alumno debía rellenar libremente.

Quizá el mayor problema a la hora de interpretar los datos obtenidos, fue la forma en que los alumnos "se tomaron" el cuestionario. Muchos lo entendieron como un examen, e intentaron aportar datos sin sentido pensando que serían evaluados de forma numérica; otros en cambio no mostraron mayor interés en la actividad, realizando respuestas sin valor alguno. Aun así centrándonos en las preguntas clave, obtuvimos datos de altísimo interés.

Como decíamos, la primera parte del cuestionario no tuvo resultados interesantes. Casi todos los alumnos cuestionados no sabían nada de Itinerarios Didácticos así como mostraron su total desconocimiento sobre los edificios incluidos en el mismo. Así sólo destacaremos aquí las que creemos son las respuestas más relevantes.

Es importante decir aquí que en el cuestionario participaron 54 alumnos, si bien al ser voluntario, alguno de ellos no contestó a todas las preguntas, de ahí la disparidad de resultados en algunas de las cuestiones. Nuevamente sería importante aclarar que no se daba ningún tipo de opción en lo que a respuestas se refiere, si no que los 
alumnos tenían total libertad a la hora de responder. La conversión en tabla posterior con los resultados, responde a una codificación espontánea de las respuestas de los alumnos, que en su mayoría respondieron sí o no, sin llegar a aportar datos de interés a las preguntas, ya que en su mayoría no tuvieron una predisposición especial a elaborar un cuestionario más completo.

Tabla 2: pregunta del cuestionario número 11

Pregunta 11: ¿Te resultan interesantes las materias de Historia e Historia del Arte?

\begin{tabular}{ccccc}
\hline ALUMNOS & SI & NO & DEPENDE & COMENTARIOS \\
\hline 54 & 39 & 13 & 2 & $\begin{array}{c}\text { Sí, me gusta mucho: } \\
1 .\end{array}$ \\
\hline
\end{tabular}

Esta pregunta resultó especialmente interesante, pues 13 alumnos dijeron no estar nada interesados en la Historia del Arte, destacando la única alumna que dijo que le gustaba mucho, como única opción que elegiría esta carrera en un posible futuro universitario.

Tabla 3: pregunta del cuestionario número 13

Pregunta 13: ¿Participarías en un excursión/ltinerario por Granada, para saber más de ellos y de la Historia de Granada?

\begin{tabular}{ccc}
\hline ALUMNOS & SI & NO \\
\hline 52 & 45 & 7 \\
\hline
\end{tabular}

A pesar de la falta de interés una gran mayoría de alumnos participaría en este Itinerario.

Tabla 4: pregunta del cuestionario número 14

Pregunta 14: ¿Qué tendrían que tener estos edificios para que te resultaran interesantes?

\begin{tabular}{|c|c|c|c|}
\hline $\begin{array}{c}\text { ALUMNOS A LOS } \\
\text { QUE LES PARECEN } \\
\text { INTERESANTES DE } \\
\text { POR Sí }\end{array}$ & $\begin{array}{c}\text { ALUMNOS A LOS } \\
\text { QUE NUNCA LES } \\
\text { RESULTARÍA } \\
\text { INTERESANTES }\end{array}$ & $\begin{array}{l}\text { RESPUESTAS } \\
\text { FUERA DE } \\
\text { CONTEXTO }\end{array}$ & $\begin{array}{c}\text { HISTORIAS DE MIEDO } \\
\text { O SUCESOS } \\
\text { PARANORMALES }\end{array}$ \\
\hline 9 & 2 & 25 & 9 \\
\hline
\end{tabular}

Esta fue quizá la pregunta más interesante del cuestionario, pues nunca habríamos pensado conseguir las respuestas que tuvimos. Por una parte, hubo 25 respuestas fuera de contexto, es decir comentarios que los alumnos pusieron intentando "hacerse el gracioso" usando un lenguaje coloquial. Pero por otra parte, destaca que un total de 9 alumnos dijeran que encontrarían interesantes estos edificios de: tener sucesos paranormales o historias de miedo.

Tabla 5: pregunta del cuestionario número 15

Pregunta 15: ¿Te resultarían más interesantes estos edificios si supieras que todos ellos "tienen fantasmas"?

\begin{tabular}{cccc}
\hline ALUMNOS & SI & NO & COMENTARIOS \\
\hline 54 & 52 & 2 & "Que lo sepas"-1. \\
& & Sí, Obviamente-6. \\
& & & Sí, "Muchísimo más"-2. \\
\hline
\end{tabular}


En esta pregunta, un total de 9 alumnos se mostraron muy atraídos por la "presencia de fantasmas" en estos edificios. Al tiempo 52 de los 54 encuestados vieron este elemento como un motivo de interés para conocer la historia de los edificios.

Tabla 6: pregunta del cuestionario número 16

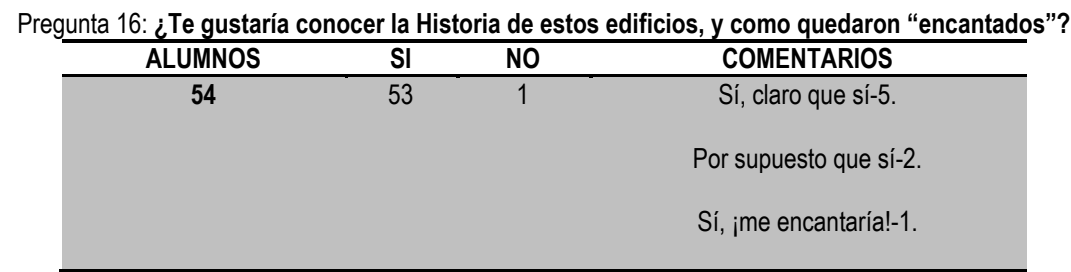

Esta fue la respuesta más mayoritaria de todas, con 53 de los 54 alumnos se interesaron por conocer las historias de los edificios, al saber que estaban "encantados". Al tiempo que 8 de ellos, se mostraron entusiasmados con la idea. Es de remarcar el elemento motivacional, ya que las respuestas mayoritarias del cuestionario fueron al saber los alumnos que la singularidad de los edificios seleccionados radicaba en el hecho de que estaban "encantados", demostrando esto que, al menos para los alumnos de $2^{\circ}$ y $3^{\circ}$ de E.S.O del Centro Ave María de Albolote, este Itinerario por edificios "encantados" suponía un elemento de motivación para conocer la historia y patrimonio de su ciudad.

\section{6.- El desarrollo del Itinerario}

El patrón para el desarrollo del Itinerario sería siempre el mismo; es decir, visita al edificio en cuestión si fuera posible, explicación magistral, exposición de la leyenda de fantasmas asociada al edificio, y realización de actividades.

Al igual que no había espacio en este artículo para desarrollar el Cuestionario íntegro, tampoco ha lugar a desarrollar el Itinerario como tal. Nos remitiremos a espacios y piezas fundamentales y a la propuesta de actividades.

\section{1.-Casa de Castril}

Situada en la Carrera del Darro, es una esplendida casa palaciega del siglo XVI, con bellísima portada plateresca y un interesante balcón cegado en esquina, que bebe de la tradición traída de Italia por Andrés de Vandelvira. Destacan el Zaguán de su entrada así como su escalera que da acceso al patio porticado, con fuente central. La amplia escalera que da acceso a la planta superior, está cubierta por una bella armadura mudéjar. La casa, como tal, perteneció a la familia Zafra, señores de Castril, como aún hoy podemos ver en el escudo de su fachada. El Museo Arqueológico quedó instalado en ella en 1879 (Jerez Mir, 2003: 148).

Su leyenda de Fantasmas, aquella de la joven Elvira, hija de Don Hernando que murió encerrada en la habitación de la ventana cegada debido al castigo por un amor 
prohibido, es una de las más conocidas a día de hoy en la ciudad (Casares, Arcos, 1999: 73-90).

Aprovechando el hecho de que el edificio alberga el Museo Arqueológico Provincial, encargaríamos la siguiente tarea: propondremos a nuestro alumnado la formación de grupos de trabajo, para realizar la siguiente actividad: deberán seleccionar por grupo una pieza del Museo Arqueológico, sobre la cual investigarán: época, estilo, procedencia, etc, para posteriormente realizar un mural, que será explicado en clase y colgado en el aula. Cada visita incluirá también la búsqueda de una serie de palabras, como vocabulario específico sobre cada edificio, en esta caso serán: Nobleza, Manierismo, Grutescos, Arqueología, Artesonado.

\section{2.-Real Chancillería.}

El edificio data de la década de 1520, bajo trazas, del maestro Francisco del Castillo. Será en 1500 cuando por orden de los Reyes Católicos, y con idea de ennoblecer la ciudad, se decida trasladar a Granada la Real Chancillería desde Ciudad Real, eso sí, ocupando distintas dependencia a lo largo de la urbe, hasta que su nieto, el Emperador Carlos V, decidiera la construcción de tan majestuoso palacio en la Plaza Nueva (Gómez-Moreno, 1998: 400-404).

Será en época de Juana I de Castilla cuando el traslado sea efectivo. Una vez establecida la Chancillería en Granada, esta tenía potestad en toda Andalucía, Reinos de Granada y Murcia, Provincias de Extremadura y de la Mancha, y de las Islas Canarias. Así se mantuvo su estado judicial hasta 1834, cuando perdió su nombre por el de Audiencia, y teniendo poder sobre las cuatro provincias del Reino de Granada (Gallego Burín, 1982: 330-332).

Sus leyendas de fantasmas, ya que son varias esta vez, hacen siempre referencia a la figura de uno, o varios verdugos, que debieron cumplir su función a lo largo de casi quinientos años de historia. Como actividad ideada para este caso, seleccionamos: Los alumnos tendrán que trabajar individualmente, buscando en internet en que consistía la labor de los verdugos durante la Monarquía Hispánica. Además como Vocabulario específico de la Actividad, seleccionamos: Chancillería, Verdugo, Pilastras, Frontón, Sistema Judicial.

\section{3.-Real Conservatorio Superior de Música Victoria Eugenia.}

Edificio de Renacimiento avanzado, según dice (siglo XVII), es de estilo sencillo y severo, todo de ladrillo y con dos torres laterales rematadas por arcos. También dice que el patio y la escalera estuvieron decorados con azulejos de talavera, habiendo sido, según, cuenta, Facultad de Farmacia, antes de su restauración para convertirlo en el Real Conservatorio. Restauración en la que se le añadió un nuevo espacio, la Sala de Conciertos, que ocupa el lugar que antes pertenecía el diario Ideal, hasta que fue incendiado en las Revueltas Anticlericales de los años treinta (Gallego Burín, 1982: 283).

En este caso la leyenda nos llega por boca de tres antiguos miembros del Conservatorio: el Director: Miguel Carmona, el Catedrático: Enrique Rueda y el profesor Nicanor de las Heras. Esta nos habla de un profesor expulsado del 
Conservatorio, (apodado Felipe, por Carmona), por no tener título, a pesar de poseer gran experiencia. Tanta fue la pena, que tras su muerte se convirtió en un alma en pena que vagaba por su querido edificio. Prueba de su presencia era un Minueto tocado al piano que Carmona decía escuchar en las noches, cuando se encontraba solo en el Conservatorio (Casares, Arcos, 1999: 91-107).

En este caso, además de la visita y la explicación tanto de su historia y de sus elementos más destacables en el aspecto histórico-artístico, podríamos concertar con el Conservatorio algún tipo de demostración musical por parte de los alumnos del mismo para nuestro estudiantado. la actividad a realizar en este caso será: Los Alumnos deberán buscar el origen de las notas musicales. Y como Vocabulario Específico: Conservatorio, Ventana Serliana, Zapata, Arco Carpanel, Minueto.

\section{4.- Hospital Real.}

El Hospital pretendía aglutinar los servicios hospitalarios de la capital. Su construcción data de 1511, cuando Fernando el Católico da la Real Cédula. (Guzmán, 2010: 62-63).

El edificio pertenece a modelos italianos dados por Filarette en el Hospital Mayor de Milán, aunque a menos escala, siendo parecido a los otros dos Hospitales fundados por los Reyes Católicos: Toledo y Santiago. Las partes meramente Renacentistas, pasan al conocido como Patio de los Mármoles y a la portada monumental. (Gallego Burín, 1982: 310-314). También destaca su Cimborrio, sito en el Crucero, de eminente decoración Gótica.

En cuanto a su historia de fantasmas se reduce a voces, pasos y demás fenómenos incorpóreos atribuidos en demasiadas ocasiones al famoso incendio que asoló el edificio en 1549, y en el que fue protagonista San Juan de Dios, sobre el que versan muchas de las apariciones. Por tanto la actividad en este caso será: Buscar información sobre la vida y obra de San Juan de Dios, dividiendo la clase en grupos nuevamente, pero distintos a los realizados en la primera actividad para fomentar la sociabilización de nuestros alumnos. Como Vocabulario especifico: Cimborrio, Gótico Isabelino, Garrote, Plataforma Ambrosio de Vico, Modelo de Hospital de Filarette.

\section{7.-Competencias.}

Remitimos las competencias trabajadas en el siguiente cuadro:

Competencia Lingüística
El alumno trabajará con nuevo vocabulario específico del tema, y específico de la Arquitectura del Renacimiento, así como de la relacionada con la enseñanza-aprendizaje de la Música, una de las siete arte. Así como vocabulario de la época renacentista y de la Historia del Arte en general

\begin{tabular}{cc}
\hline Competencia Digital & E \\
Competencia Aprender a Aprender & C
\end{tabular}
El alumno trabajará con fuentes on-line para realizar las actividades, y tendrá que seleccionar el origen y calidad de la información.

Creemos que el conjunto de la actividad en sí engloba esta Competencia, pues será un elemento motivador para fomentar el conocimiento de la Historia e Historia del Arte de estos edificios, así como de la propia Ciudad, al tiempo que 


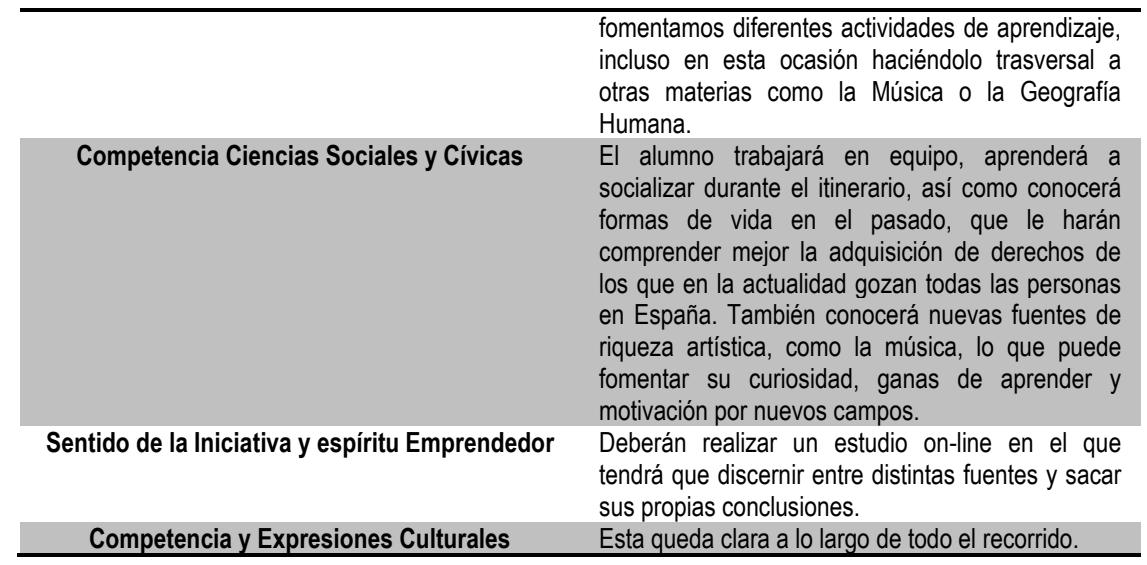

\section{8.-Criterios de Evaluación.}

\begin{tabular}{|c|c|}
\hline TAREA & EVALUACIÓN \\
\hline \multirow[t]{2}{*}{$\begin{array}{l}\text { Casa de Castril: Seleccionar una pieza del } \\
\text { Museo Arqueológico y realizar una } \\
\text { investigación grupal sobre la misma, donde se } \\
\text { realizará un mural con: fechas, cultura que la } \\
\text { desarrolla, formas de vida, ubicación, estilo } \\
\text { artístico, etc }\end{array}$} & $\begin{array}{l}\text { El mural, será expuesto en clase de forma grupal, } \\
\text { se evaluará: la calidad de la información, así como } \\
\text { de la realización del propio mural, el trabajo } \\
\text { colaborativo, y las habilidades sociales y de } \\
\text { expresión en público delante de sus compañeros. }\end{array}$ \\
\hline & EVALUACIÓN \\
\hline $\begin{array}{l}\text { Real Chancillería: buscar, bien en internet, o en } \\
\text { Bibliografía, información sobre la labor de los } \\
\text { Verdugos en España. }\end{array}$ & $\begin{array}{l}\text { Entrega de breve informe sobre la tarea } \\
\text { encargada, se valorarán: fuentes consultadas, } \\
\text { calidad de la Información, habilidades de redacción } \\
\text { y expresivas, y juicios propios obtenidos por el } \\
\text { alumno sobre la labor de los verdugos y la no } \\
\text { existencia de este personaje en la Sociedad actual. }\end{array}$ \\
\hline TAREA & EVALUACIÓN \\
\hline $\begin{array}{l}\text { Real Conservatorio Superior de Música Victoria } \\
\text { Eugenia: se encarga como tarea la búsqueda } \\
\text { del origen de las notas musicales. }\end{array}$ & $\begin{array}{l}\text { De nuevo se entregará un pequeño informe con la } \\
\text { información sobre el tema. Se valorará la calidad } \\
\text { de las fuentes y la veracidad de lo expuesto en el } \\
\text { citado informe. }\end{array}$ \\
\hline TAREA & EVALUACIÓN \\
\hline $\begin{array}{l}\text { Hospital Real: se encarga como tarea, buscar, } \\
\text { de forma grupal, información sobre la vida y } \\
\text { obras de San Juan de Dios. }\end{array}$ & $\begin{array}{l}\text { Se entregará pequeños trabajo grupal con la } \\
\text { información solicitada, valorándose: calidad de las } \\
\text { fuentes, relevancia de la información encontrada y } \\
\text { veracidad de la misma, capacidad social del } \\
\text { alumno y de trabajo en equipo. }\end{array}$ \\
\hline
\end{tabular}

\section{9.-Conclusiones}

Creemos que esta propuesta supone una puesta en valor del patrimonio local a través de las materias incluidas en los Contenidos Curriculares, con especial atención a los procesos de transformación de la ciudad durante la Reconquista y el proceso renovador de los Reyes Católicos. Trabajamos las clases sociales, los distintos estilos artísticos y su desarrollo temporal, así como sus principales elementos estilísticos, entendiendo también que la elección del tema (las historias de 
fantasmas) suponen un verdadero acicate para el alumnado, como ha dejado patente el cuestionario realizado al alumnado de $2^{\circ}$ y $3^{\circ}$ de la E.S.O del Centro Ave María de Albolote. Por tanto valoramos esta práctica como integradora, transversal, motivacional e ilustrativa, mediante una forma original de transferir el conocimiento. Además creemos que también queda acreditado que los Itinerarios suponen una buena forma de sociabilizar a nuestro alumnado, especialmente a los que tengan problemas para relacionarse con sus demás compañeros. También utilizaremos los trabajos en grupo como forma de integración de nuestro alumnado, convirtiendo así esta práctica en un elemento claramente inclusivo.

\section{0.-Referencias.}

Arias Romero, S.M., Contreras García, J., Guerrero Castellón, M. I., Moscoso Jiménez, J.M. (2018). Granada y la Vega: Patrimonio Olvidado. Itinerarios Didácticos para el estudiantado del Grado de Educación Primaria. Granada: Fleming.

Arias Romero, S.M., Contreras García, J., De Czestochowa Molina Serrano, M., Tenedor Tenedor, J. (2018). El Patrimonio Granadino como Elemento Didáctico: un Itinerario Inclusivo por el Barrio de la Manigua. Inclusión y Diversidad: intervenciones socioeducativas. Madrid: Wolter Kluwer.

Carta de los Itinerarios Culturales elaborada por el Comité Científico Internacional de los Itinerarios Culturales (CIIC) del ICOMOS. Ratificada por la 16a Asamblea General del ICOMOS, Quebec (Canadá), el 4 de octubre de 2008.

Gallego Burín, A. (1982) Granada. Guía artística e histórica de la ciudad. Granada: Don Quijote.

García Ruiz, A.L., Jiménez López, J. A. (2006). Los Principios Científico-Didácticos $(P C D)$ : nuevo modelo para la enseñanza de la Geografía y de la Historia: fundamentos teóricos. Granada: Universidad.

Gómez-Moreno, M. (1998). Guía de Granada. Granada: Universidad. [Edición facsímil del original de 1892, Granada: Imprenta de Indalecio Moreno].

Guzmán Pérez, M. (2010). Granada. Urbanismo y núcleos monumentales. Proyección educativa. Granada: Zumaya.

Isac, A. (2007). Historia urbana de Granada: formación y desarrollo de la ciudad burguesa. Granada: Diputación.

Martínez, T., López, V., Santacanamestre, J. (2016). La educación patrimonial como herramienta para la educación inclusiva: definición, factores y modelización. Andamio | Revista de la didáctica de la historia, v. 2, n. 3, p. 81-97. 
Revista Internacional de Apoyo a la Inclusión, Logopedia, Sociedad y Multiculturalidad. Volumen 5, Número 3, Diciembre 2019, ISSN: 2387-0907. DOI: https://doi.org/10.17561/riai.v5.n3

Viñes Millet, C. (1987). Historia urbana de Granada. Su evolución hasta finales del siglo XIX. Granada: Centro de estudios municipales y de cooperación interprovincial. 